\title{
Critical Analysis of Postgraduate Students Online Learning Style During COVID-19 Public Health Crisis
}

\author{
Rasika Jayasekara* \\ Senior Lecturer in Nursing \& Midwifery, UniSA Clinical \& Health Sciences, City East Campus, Australia \\ *Corresponding author: Rasika Jayasekara , Senior Lecturer in Nursing \& Midwifery, UniSA Clinical \& Health Sciences, \\ City East Campus, North Terrace, Adelaide SA 5000, Australia
}

\begin{abstract}
ARTICLE INFO
Received: 幽 July 14, 2020

Published: 慧 August 20, 2020

Citation: Rasika Jayasekara. Critical Analysis of Postgraduate Students Online Learning Style During COVID-19 Public Health Crisis. Biomed J Sci \& Tech Res 29(4)-2020. BJSTR. MS.ID.004834.

ABSTRACT

Online web-based learning which is a unique form of distance education has been widely utilized in the higher education sector around the world. It is reported that significant growth in online programs enrollments during the last five years with one in five students now selecting to study online. The purpose of this critical analysis was to explore a group of postgraduate students online learning style during COVID-19 public health crisis. Overall, the use of Zoom Virtual classroom and online forum discussion for postgraduate students may be an effective and practical approach to support student learning. However, several challenges were exposed mainly the application of technology, student participation and acceptance of online teaching methods, students learning styles and educators support to the student learning.
\end{abstract}

Keywords: Online Learning Style; Online Education; Postgraduate Students; Covid-19

\section{Introduction}

Nursing programs of the University of South Australia are considered as one of the largest nursing programs in Australia. More than 2500 undergraduate and postgraduate students are enrolled in various nursing and healthcare specialty programs. The online learning community selected for this assignment was first-year postgraduate students enrolled in newly started Master of Health Services Management (IMHM). This program is designed to develop students' knowledge and skills in management, administration, leadership, project management, strategic management, financial management within a two-year full-time study [1]. During the first semester (study period 1,2, and 3) full-time students should complete four 4.5 unit courses including a research methodology course (NURS 5152- Quantitative Design for Nursing, Midwifery and Health Research). The purpose of this research course is to develop skills in designing rigorous quantitative research to inform knowledge, practice, management and policy in nursing, midwifery, and health-related fields [2]. During the 13-weeks of the course, students are required to complete six topics and two major assignments to meet the course objectives. This course was offered both internal and external delivery; however, all internal classes were moved online due to COVID-19 public health crisis after the initial two weeks of the teaching period.

\section{Targeted Community}

Two online classes of the NURS 5152 course with 60 postgraduate students were selected for this task. The selected cohort is comprised of a mixture of young and mature-aged students from various backgrounds, including full-time healthcare professionals, interstate, and international students. The majority of students are considered as international students mainly from India. It is a visa requirement that international students should be able to study on-campus internal mode; however, it appears that majority of students enjoy studying online because it allows the student the flexibility in balancing social and academic commitments [3]. Online education has increasingly been used in the university education sector around the world [4]; however, student satisfaction and retention in online programs are problematic [5].

\section{Method of Observation and Tool}

As the lecturer of this course (NURS 5153), I observed 60 
postgraduate students during fortnightly online Zoom workshop sessions at week 3- Understanding different quantitative research designs (before the first assignment Part A), week 5- Establishing scientific rigor and critical appraisal, week 7 - before the Assignment 1 Part B, Week 9 - Approaches to analyzing, interpreting and reporting quantitative data, and Week 10 -Assignment Two: Interpreting quantitative statistical techniques and summary presentation (question and answer session). The observation of selected online learning community was conducted using Zoom virtual classroom which is a 'real-time', synchronous online interactive tools and increasingly been used to replicate a face to face classroom [6] during the last six months due to COVID-19. Also, the online discussion forum was used to observe the student learning style. A variety of activities including posting scenarios, images, embedded audio, and video contents followed by relevant activities were utilized to interact with students in a meaningful way. In both Zoom sessions and online forum are guided by InquiryBased Learning [7] where students are encouraged to explore the issue/problem, finding the solution and share ideas. Also, students were encouraged to support; learn and mentor each other on the discussion forums in light of peer learning can improve the overall quality of student learning [8].

\section{Outcome and Analysis}

Use of Online Learning Tools: Fortnightly Virtual Classrooms (VCs) using Zoom and online discussion forum are the key online learning tools utilized to observe the selected online learning community. The lesson plans and relevant activities were provided to the students in advance, enabling students to prepare for the VC. The VC is guided by a PowerPoint presentation which included the objectives of the lesson, key learning content from the weekly topics, activities/tasks and sample writing related to the assessments. Based on the pre-planned activity (e.g. developing a research question; selecting critical appraisal tools), four to five students were allocated to break out rooms to work together as a group followed by a large group presentation. During the small group discussions, the lecturer accessed to individual groups and joined the discussion. All Zoom VC sessions were recorded, and Panopto, which is used as a Lecture Recording System (LRS) was used to edit and share the recorded video. UniSA Panopto folder location was sent via email and online forum posting to all students enabling them to access the recorded VCs. The online forum was also used to enhance students' learning outcomes. Weekly online forum discussion was set up, allowing the students to access the forum anytime that makes student and teacher to managing their work/ study life balance. The forum discussion included a summary of the weekly content, external resources embedded audio and video files followed by relevant activities. Forum subscription function allows students and teacher to receive notifications of new forum posts.
Overall, most students expressed that Zoom VC and Online Forum were useful and interactive, especially assessment guidance using step by step approach and sample writing provided. Based on the student feedback, Zoom is quite intuitive, and the most attractive feature is a High Definition (HD) video and audio that provide exceptional clarity and quality to virtual classes in comparison with Adobe Connect VC. Students reported that online forum and Zoom VC were designed to strengthen interaction amongst students, and 'teacher-presence' plays a crucial role in building a sense of belonging to the learning community and in improving student retention [9]. However, it is observed that maintaining a strong sense of 'teacher-presence' in online education (e.g. responding online forum postings, emails) is time-consuming and is not always recognized in existing workload models. It was also noted that students are seeking a flexible way to access Zoom VC and are increasingly used mobile devices; thus, university education should address the needs of diverse students enabling them to reach the best possible learning outcomes.

Internationally, higher education institutions are transforming to maximize the student learning outcomes integrating digital online technology with a human-centric focus [10]. However, the amalgamation of online learning to the education programs should be carefully examined in terms of students' acceptability and completion rates compared with traditional on-campus education. A research of 151 members of academic and professional staff across 16 higher education institutions in Australia and United Kingdom reported that the retention rate of online students was at least $20 \%$ lower than compared with on-campus programs and the online degree completion rate is also considerably lower [11]. Despite this fact, a large number of individual studies showed the positive learning outcomes of online learning strategies [12-16]. Interestingly a meta-analysis of 50 studies conducted by the U.S. Department of Education does not demonstrate that online learning is superior to face-to-face instruction; however, this study found that combining online and face-to-face strategies had a considerable advantage compared with entirely face-to-face instruction or online instruction [17]. The important fact is that most studies related to online learning were conducted by university academics who used their courses; therefore, the generalizing the findings to the education practice should be carefully evaluated.

Online Learning Community and Outcomes: It was noted that student participation of online forum and Zoom VC are notably weak compared with face to face tutorials. I also observed that students were reluctant to use their microphone or video, but it appeared that the text chat was widely used in which active interaction and discussion were limited. It was often noted that students went missing during Zoom VCs assuming students logged in to Zoom to record their attendance only, sometimes it was not clear whether students were actually participating because of 
there was no sign of interaction. Also, it was observed that students preparing to the Zoom VC was inadequate; particularly it was noted that when working in small groups within the breakout rooms because knowledge on the required course content was limited. Zoom VCs microphone privilege was offered to students enabling them to interact with the lecturer and other students; however, only a few students have used the microphone to ask questions or answer the questions. Similarly, online forum discussions were somewhat limited to assessment task discussions; therefore, it was not clear whether the students utilized the forums effectively to engage the course content and subsequent activities. As a result, topic activities were modified and linked to the assessment task (e.g. posting their research question and hypothesis to the forum for the approval).

Culture plays an essential role in the cognitive development of learners through social interaction and discourse [18]. Sociocultural learning theories indicate that student's perception of reality is a product of the socio-cultural process, and all knowledge is socially mediated, which is grounded in culture [19]. The majority of students were international students from different cultural backgrounds; thus, the level of engagement and interaction may be limited mainly due to language barriers. Some studies found that online learners use different communication styles across cultures [20]. Hence, the cultural aspect of learning needs to be adequately addressed in designing and delivering education programs [21,22]. Kim \& Bonk reported from their previous studies; most Asian students had been tutor-oriented learners in their native countries, and their learning strategy is heavily based on direction from their lecturers even in the self-directed online learning environment. In contrast, most local students appeared to be self-directed learners who showed independent learning [23]. The constructivist philosophy guides educators to build a nurturing and, self-sustaining online learning community enabling learners to evaluate and reflect on the development essential to their own learning [24]. During the Zoom sessions, students were encouraged to be active learners through brainstorming, discussion, debate and problem-solving. In a constructivist learning environment is established and reinforced when educators and learners interact in a manner that demonstrates genuine caring for each other, which in turn translates into increased learning and teaching efficacy [25]. Furthermore, the research found convincing evidence for the correlation between constructivist teaching approaches and a positive learning environment [26], further research should be conducted to identify individual variables of student demographics to determine the effective online teaching strategies.

It was observed that some students, and particularly the matured students, were exposed to high-demand technology learning due to transferring their face to face teaching to entirely online due to COVID-19 restrictions; however, the majority showed positive attitudes towards the new learning approach. It appeared that some students had taken the opportunity to interact with other students concurrently in the online Zoom sessions and online discussion forum. Several students, however, revealed that, compared with face-to-face teaching, online learning in particular forum postings rather time-consuming. Students' learning expectations and satisfaction with the course content and subsequent activities were somewhat diverse and unpredictable. While some students considered the course content as being productive and helpful, others dissatisfied with them. It was observed that students' perceptions of online education were positively associated with their sense of teacher immediacy, which remains an important factor towards effective pedagogical methods. I believe that students need to perceive the tutor as a 'real person'; therefore, I utilized my professional expertise and personal experience to discuss course content and providing timely, personalized, and constructive feedback on student assessment tasks. High-quality constructive and timely feedback is considered as a vital aspect of the assessment process in terms of improving student performance and meeting the course objectives and in establishing strong relationships between academics and students.

Based on my teaching experience and this observation, online education using web-based content, online forum and VCs is somewhat limited in comparison to the traditional face to face teaching. However, a large systematic review of 232 studies involving more than 57,000 students found no statistically significant difference in students' learning outcomes in both methods. It appears that a mixture of both traditional classroom teaching and online education would be the best answer even though the blended learning research provided no explicit agreement on their relative proportions. However, University of South Australia Digital Learning Strategy 2015-2020 suggested that on-campus students will have the option to complete a minimum of $25 \%$ of their studies online (Strategic Priority 3.2) which may help students to manage study-life- work balance. Based on two systematic reviews and six meta-analyses on the effectiveness of blended learning, Siemens, Gasevic and Dawson concluded that blended learning is an effective teaching strategy compared with fully face to face teaching or online delivery modes [17]. However, further studies should be conducted to find the most effective online teaching methods with measurable student learning outcomes.

\section{Conclusion}

In this study, fortnightly VCs using Zoom and online discussion forum tools utilized to observe the selected online learning community: first-year postgraduate students. Overall, the use of Zoom VC and online forum discussion for new students may be an effective and practical approach to support student learning. However, several challenges were exposed mainly the application of 
technology, student participation and acceptance of online teaching methods, students learning styles and educators support to the student learning. Blended learning- a mixture of both traditional classroom teaching and online education would be the best answer; however, new technology integration should be carefully evaluated in terms of availability of technology, students, and academics preference.

\section{References}

1. Bernard (2009) A meta-analysis of three types of interaction treatments in distance education. Review of Educational Research 79(3): 12431289.

2. Bliuc AM, Ellis R, Goodyear P, Piggott L (2010) Learning through face-to-face and online discussions: Associations between students conceptions, approaches, and academic performance in political science. British Journal of Educational Technology 41(3): 512-524.

3. Bremgartner V (2015) Adaptation resources in virtual learning environments under constructivist approach: A systematic review. 2015 IEEE Frontiers in Education Conference (FIE) 21-24 pp. 1-8.

4. Brown L (2014) Constructivist Learning Environments and Defining the Online Learning Community. Journal on School Educational Technology 9(4): 1-6.

5. Gaspar A, Langevin S, Boyer N, Armitage W (2010) Students' Activity Focus in Online Asynchronous Peer Learning Forums. Informatics in Education 9(1): 19.

6. Gazza EA, Hunker DF (2014) Facilitating student retention in online graduate nursing education programs: a review of the literature. Nurse Education Today 34(7): 1125-1129.

7. Ghamdi A, Samarji A, Watt A (2016) Essential Considerations in Distance Education in KSA: Teacher Immediacy in a Virtual Teaching and Learning Environment. International Journal of Information and Education Technology 6(1): 17-22.

8. Giles TM, Gilbert S, McNeill L (2014) Nursing students' perceptions regarding the amount and type of written feedback required to enhance their learning. J Nurs Educ 53(1): 23-30.

9. Graves JK, Goodman JT, Hercinger M, Minnich M, Murcek CM (2015) Evaluation of embedded audio feedback on writing assignments. J Nurs Educ 54(1): 41-44.

10. Hassan OAB (2011) Learning theories and assessment methodologies - an engineering educational perspective. European Journal of Engineering Education 36(4): 327-339.

11. Kim KJ, Bonk CJ (2002) Cross-cultural Comparisons of Online Collaboration. Journal of Computer-Mediated Communication 8(1).
12. Lai C (2015) Modeling teachers' influence on learners' self-directed use of technology for language learning outside the classroom. Computers \& Education 82: 74-83.

13. Lin CH, Zheng B, Zhang Y (2017) Interactions and learning outcomes in online language courses. British Journal of Educational Technology 48(3): 730-748.

14. McCarthy J (2015) Evaluating Written, Audio and Video Feedback in Higher Education Summative Assessment Tasks. Issues in Educational Research 25(2): 153-169.

15. Shadat A, Sayem M, Taylor B, McClanachan M, Mumtahina U (2017) Effective use of Zoom technology and instructional videos to improve engagement and success of distance students in Engineering. AAEE2017Conference, AAEE.

16. Shin N, Chan JKY (2004) Direct and indirect effects of online learning on distance education. British Journal of Educational Technology 35(3): 275-288.

17. Siemens G, Gasevic D, Dawson S (2015) Preparing for the digital university: a review of the history and current state of distance, blended, and online learning, Athabasca University, Unpublished.

18. Stone C (2017) Opportunity through online learning: Improving student access, participation, and success in higher education.

19. Stripling B (2008) Inquiry-based Teaching and Learning-The Role of the Library Media Specialist. School Library Media Activities Monthly 25(1):

20. Sweasey R (2019) Digital and the human: remodelling universities for the future. Campus Review 7.

21. Thomas M, Mitchell M, Joseph R (2002) A cultural embrace. TechTrends 46(2): 40-45.

22. US Department of Education, Evaluation of Evidence-Based Practices in Online Learning: A Meta-Analysis and Review of Online Learning Studies, Center for Technology in Learning, Washington, DC.

23. UniSA 2020a, Master of Health Services Management.

24. UniSA 2020b, NURS 5152- Quantitative Design for Nursing, Midwifery and Health Research, UniSA.

25. Walker S, Rossi D, Anastasi J, Gray Ganter G, Tennent R (2016) Indicators of undergraduate nursing students' satisfaction with their learning journey: An integrative review. Nurse Educ Today 43: 40-48.

26. Zhang Y, Lin CH (2020) Motivational profiles and their correlates among students in virtual school foreign language courses. British Journal of Educational Technology 51(2): 515-530.
ISSN: 2574-1241

DOI: $10.26717 /$ BJSTR.2020.29.004834

Rasika Jayasekara. Biomed J Sci \& Tech Res

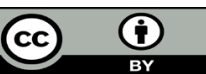

This work is licensed under Creative

Commons Attribution 4.0 License

Submission Link: https://biomedres.us/submit-manuscript.php

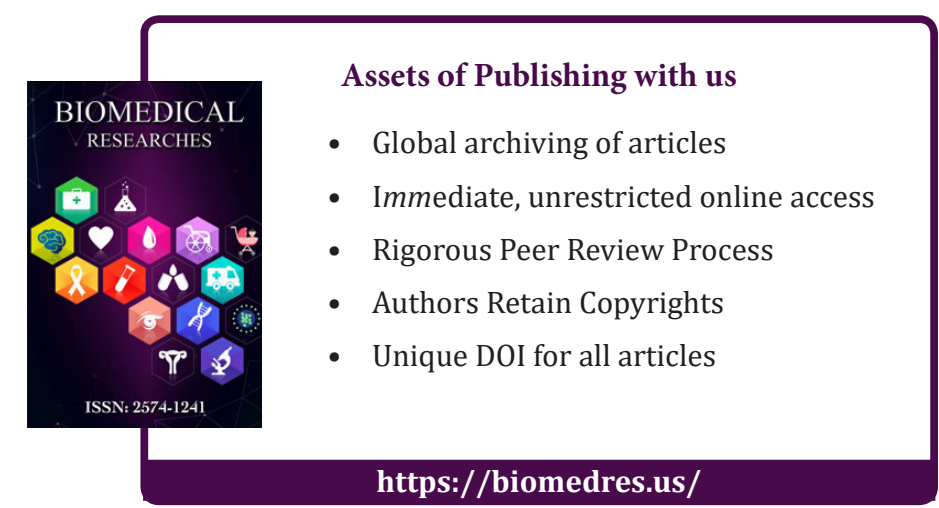

